\section{LA ETNOARQUEOLOGÍA, HOY: UNA VÍA EFICAZ DE APROXIMACIÓN AL PASADO}

\author{
ETHNOARCHAEOLOGY, TODAY: AN \\ EFFECTIVE WAY FOR LEARNING \\ ABOUT THE PAST
}

ALMUDENA HERNANDO GONZALO (*)

\section{RESUMEN}

Definir los contenidos, objetivos y metodología de la Etnoarqueología constituye una difícil tarea. Aunque el término había sido utilizado con anterioridad, su nacimiento como disciplina o heurística para el conocimiento del pasado se corresponde con el de la Nueva Arqueología americana, en tanto que una de sus Teorías de Alcance Medio. Como tal, implicaba toda una serie de asunciones teóricas rebatidas posteriormente por la corriente post-procesual. Ambas posiciones teóricas defienden modelos opuestos de concebir la Etnoarqueología, a la vez que ésta es confundida a menudo con la «Arqueología viva" o con la analogía etnográfica.

La propuesta de estas páginas es doble: por un lado, se intentará clarificar el alcance y la especificidad de la Etnoarqueología frente a otras heurísticas desde una argumentación exclusivamente teórica; por otro, se planteará un caso concreto para ejemplificar las nuevas vías de aproximación al pasado que hoy ofrece la Etnoarqueología.

\begin{abstract}
Defining the content, goals and methodology of Ethnoarchaeology is a difficult task. Although the term had been used earlier, its birth as a discipline or device for learning about the past corresponds with that of the New Archaeology in the United States. Ethnoarchaeology has become one of the New Archaeology's Middle Range Theories. As
\end{abstract}

(*) Departamento de Prehistoria. Facultad de Geografía e Historia. Universidad Complutense. 28040-Madrid.

El artículo fue remitido en su versión final el 4-IX-95. such, it implies a whole series of theoretical assumptions subsequently criticized by Post-Processualists. Both theoretical camps defend opposing models of how Ethnoarchaeology should be conceptualized. At the same time, Ethnoarchaeology is often confused with "Living Archaeology" or with ethnographic analogy.

This essay has two goals: on the one hand, it attempts, in purely theoretical terms, to clarify the scope and specific nature of Ethnoarchaeology; on the other hand, it presents a specific example that illustrates the new ways of approaching the past that Ethnoarchaeology now offers.

Palabras clave: Etnoarqueología. Analogía etnográfica. Teoría arqueológica. Antropología.

Key words: Ethnoarchaeology. Ethnographic analogy. Archaeological theory. Anthropology.

\section{INTRODUCCIÓN (1)}

La Prehistoria, como todas las Ciencias Sociales, atraviesa un momento interesante. Por

(1) Este trabajo forma parte del estudio realizado durante los meses de marzo-mayo 1995 en el Departamento de Antropología de la Universidad de California, Los Ángeles (UCLA). La estancia fue financiada por una Beca Complutense Del Amo, concedida por el Rectorado de Relaciones Internacionales de la Universidad Complutense de Madrid, y posibilitada por la hospitalidad y generosidad de aquel Departamento, pero muy especialmente del Dr. Timothy Earle, a quien deseo agradecer las facilidades que, de todo tipo, me ofreció siempre para la realización del estudio. Al Dr. Antonio Gilman no sólo debo la posibilidad de haberlo iniciado, sino el haber conseguido, junto a Benedicte Gilman, hacerme sentir que Los Ángeles es una ciudad a la que cuesta trabajo abandonar. 
un lado, las tendencias historicistas que han dominado su historiografía nos han permitido disponer en la actualidad de una sólida reconstrucción histórica de la mayor parte de las secuencias culturales en cada una de las zonas. La investigación centrada en la tipología o en la cronología de los restos materiales empieza, por ello. a resultar poco estimulante incluso a quienes siguen manteniendo posiciones historicistas.

Pero, sobre todo, muchas de las premisas sobre las que construía su conocimiento parecen puestas en cuestión. El desarrollo de las posiciones post-procesuales, $\tan$ insertas en la «Postmodernidad", hicieron tambalear la seguridad ontológica que parecían desbordar quienes confiaban en las posibilidades explicativas de los grandes modelos tradicionales - léase Materialismo Histórico o Ecología Cultural, por ejemplo- Sin embargo, el relativismo en el que algunos se dejaron caer no ofrecía ninguna alternativa válida que estimulara los estudios prehistóricos. ¿Para qué estudiar el pasado, si era imposible conocerlo?

Dentro de este clima de duda e incertidumbre, de pérdida generalizada de las grandes convicciones de antaño, comenzamos a asistir al nacimiento, reposición o desarrollo de determinadas tendencias de análisis que empiezan a marcar un nuevo período en la Historia de la disciplina. Los nuevos acercamientos no consisten en la profundización epistemológica o en la discusión teórica de los antiguos modelos. Se alejan, igualmente, del énfasis frustrante en la toma de conciencia del subjetivismo inherente a todo conocimiento. En general, se trata de propuestas que tratan de encarar el conocimiento del pasado prehistórico desde vertientes diferentes a las tradicionales, en las que la cultura material constituía el único foco de interés. Aún si se trataba de integrar esta información en sólidas propuestas teóricas, los resultados tendían en general a centrarse en los aspectos materiales de las culturas, aquellos que se consideraban más susceptibles de contrastación empírica. Sin embargo, últimamente parece constatarse un interés por descubrir pautas más amplias de funcionamiento de las culturas, en las que tenga cabida la interrelación entre construcción simbólica y material de la sociedad, la lógica interna que posibilita la supervivencia de determinadas formas culturales.

Es en este sentido en el que creo puede definirse una de las aportaciones de la Etnoarqueo- logía al conocimiento de la Prehistoria europea. Ciertamente. la Etnoarqueología constituye la continuación de una ya larga tradición de estudio, iniciada en Estados Unidos a raíz de la evidente conexión entre restos arqueológicos y antepasados de los grupos indígenas actuales. Pero últimamente, las discusiones teóricas que está suscitando se presentan bajo una sensibilidad profundamente diferente, por lo que me parece interesante analizar cuáles pueden ser sus aportaciones actuales al estudio de la Prehistoria europea. Para ello, será necesario acotar primeramente el término definiendo su contenido, cuestión en absoluto cerrada ni mucho menos consensuada por quienes practican la Etnoarqueología. En segundo lugar, utilizaré, a modo de ejemplo del alcance y posibilidades que puede ofrecer hoy la Etnoarqueología, el planteamiento de un caso de estudio, sólo iniciado por el momento, entre los kekchíes de Alta Verapaz, Guatemala.

\section{LA ETNOARQUEOLOGÍA: DEFINI- CIÓN, OBJETIVOS, CONTENIDO}

Como se sabe, la Antropología americana fue la primera en relacionar evidencia arqueológica y comportamiento etnográfico, dada la relación directa entre los restos arqueológicos que se estaban excavando y los sucesores, vivos, de los grupos indígenas que los habían producido (Gould, 1974: 29). De hecho, la palabra «etnoarqueología» fue utilizada por primera vez en 1900 por Jesse W. Fewkes, para referirse a sus intentos de identificar yacimientos Hopi asociados tradicionalmente por los indios Hopi actuales a determinados mitos (Oswalt, 1974: 5). Por su lado, Pitt Rivers fue el primero en dar cabida en los estudios antropológicos a la cultura material, a través de sus análisis sistemáticos de colecciones etnográficas a principios de siglo (Oswalt, 1974: 9).

Sin embargo, no fue hasta 60 años después cuando empezó a hablarse de etnoarqueología como una disciplina con identidad propia. Mientras, artículos como el de Julian H. Steward (1942) habían tratado de llamar la atención sobre la importancia de las fuentes etnográficas para los estudios prehistóricos, pero sin mayores consecuencias. En 1958 se produce el primer intento monográfico de analizar informes etnográficos sobre cultura material con una perspec- 
tiva arqueológica (Thompson, 1958), y es en 1967 cuando vuelve a aparecer el término «etnoarqueología" en un estudio de Oswalt y VanStone sobre la cultura material, y la información oral que sobre ella podía conseguirse, de un yacimiento esquimal ocupado entre 1840 y 1910 (Oswalt, 1974: 5).

Pero los desarrollos existentes hasta ese momento no integraban en realidad una nueva disciplina. Se trataba, simplemente, de analizar con "perspectiva arqueológica" la cultura material de pueblos actuales, sin otras implicaciones o elaboraciones teóricas. En realidad, el nacimiento de la etnoarqueología como una disciplina con identidad propia, sobreviene con el desarrollo de la Nueva Arqueología americana. L.R. Binford, su principal representante, preocupado por el tema de la analogía etnográfica desde fechas tempranas (Binford, 1967), comenzó a desarrollar estudios sistemáticos, caracterizados por la exhaustividad en la recolección de información, sobre la utilización y dispersión de la cultura material entre los Nunamiut de Alaska (Binford, 1978).

De esta manera, una de las manifestaciones de la Nueva Arqueología (no olvidemos que uno de los hitos que marcan su constitución como corriente de pensamiento fue el artículo de Binford (1962) «Archaeology as Anthropology») fue el desarrollo de estudios sobre grupos actuales para derivar analogías útiles a la comprensión del modo de vida de los grupos prehistóricos. Como ya ha sido señalado en otro lugar (Fernández Martínez, 1994: 138), los trabajos de R. Lee e I. de Vore $(1968,1976)$ o J. Yellen (1977) con los bosquimanos africanos, de R. Gould $(1978,1980)$ con los aborígenes australianos o el citado de Binford (1978), son utilizados como contextos-fuente de analogías con el modo de vida paleolítico; los de B. Hayden y A. Cannon $(1983,1984)$ y M. Deal (1985) en Mesoamérica o los de C. Kramer (1982) en Irán, para profundizar en el conocimiento de culturas desde el Neolítico a la Edad del Hierro, etc., etc..

Ahora bien, todos estos desarrollos compartían un cuerpo teórico y unas asunciones básicas perfectamente definidas. Como sabemos, la Etnoarqueología formaba parte de la Nueva Arqueología en tanto que una de sus llamadas Teorías de Alcance Medio. Es decir, se trataba de un intento de elaborar generalizaciones en forma de ley que dieran cuenta de las condiciones -económicas, sociales, ambientales o ideo- lógicas - en las que un determinado tipo de comportamiento o el material que resulta de ese comportamiento pueden aparecer. Las Teorías de Alcance Medio son generalizaciones de nivel medio que intentan conectar el estático registro arqueológico con la dinámica actividad social de la que es resultado. No intentan dar explicaciones globales sobre procesos de cambio cultural, sino llegar a conocer qué tipos de comportamientos pueden originar los conjuntos de cultura material que encontramos en los yacimientos. Por todo ello, la Etnoarqueología asume principios a) evolucionistas y b) positivistas.

a) Los primeros, porque su aplicabilidad reside en la convicción de que existen similitudes entre distintos procesos de transformación cultural; que existen condiciones de comparabilidad entre desarrollos culturales diferentes, porque los grupos humanos se transforman siguiendo unas tendencias que pueden generalizarse. Se ha denominado "uniformismo" a esta asunción.

b) Los segundos, porque considera que existe una correlación que se repite entre determinados comportamientos humanos y el registro material que producen, por lo que, averiguada dicha correlación en grupos vivos, puede suponerse la misma en grupos del pasado. Se asume así que el registro material es un reflejo directo del comportamiento humano.

Ahora bien, semejantes presupuestos fueron seriamente discutidos desde las posiciones postprocesuales, que propusieron un enfoque esencialmente diferente para este tipo de estudios. Como sabemos, la arqueología «contextual» proponía la sustitución de las Teorías de Alcance Medio por el análisis del contexto social y conceptual de la producción de la cultura material (Hodder, 1988: 141). A su juicio, una relación cultural universal entre lo estático y lo dinámico resulta imposible, dado que intervienen los principios de estructuración, históricamente contextuales. Así pues, la Etnoarqueología debería estudiar cada cultura desde «el interior», para comprender las pautas culturales de cada caso, inseparables por cierto, «del sentido estético y de la calidad emocional del deseo, del orgullo, etc.» (Hodder, 1988: 142).

Como vemos, definir el contenido y alcance de la Etnoarqueología no es fácil. Para hacerlo, habría que comenzar por aclarar y definir sus objetivos, metodología y presupuestos, para lo cual parece oportuno intentar disolver ciertas 
confusiones y solapamientos con estudios que, a mi juicio, no pueden definirse como etnoarqueológicos si utilizamos el término sensu strictu. Sin embargo, así se autodefinen en la bibliografía. De hecho, en un excelente trabajo de síntesis, V. Fernández Martínez (1994: 137) ofrece el amplio espectro de trabajos que podemos encontrar bajo ese epígrafe. Para ello, diferencia dos definiciones de Etnoarqueología: una en sentido amplio y otra en sentido estricto. La primera incluiría todas las relaciones entre Antropología y Arqueología, desde la utilización de paralelos etnográficos aislados a la interpretación arqueológica, hasta la elaboración de leyes transculturales generales. La segunda haría alusión al trabajo de campo etnográfico realizado con criterios arqueológicos, para obtener información relativa a la cultura material, aspecto descuidado por los antropólogos tradicionales. A partir de ahí, pasa revisión a los principales resultados concretos (clasificados en los concernientes a «la formación del depósito arqueológico", «tecnología y subsistencia», "organización social" y «arte y ritual»)(v. también Orme, 1981). Ahora bien, ¿pueden considerarse etnoarqueológicos todos los trabajos que así han sido denominados si nos atenemos estrictamente a la definición y contenido original del término?

A mi juicio, en un orden de progresiva abstracción, puede hacerse alusión a tres focos de confusión general alrededor de la Etnoarqueología que nos ayudarán a definir su alcance y contenido:

1) el que se refiere a su identificación con los procedimientos y técnicas empleados para la obtención de información de primera mano utilizable en un razonamiento analógico.

2) la identificación entre Etnoarqueología y Analogía Etnográfica.

3) la definición del ámbito cultural objeto de estudio por parte de la Etnoarqueología.

\subsection{Etnoarqueología $\mathbf{y}$ «Arqueología viva»}

Desde comienzos de siglo, como veíamos al principio, se ha identificado a veces la Etnoarqueología con el estudio de la cultura material de pueblos vivos desde una perspectiva arqueológica.

De hecho, la Antropología ha olvidado sistemáticamente la cultura material como parte esencial de la definición de cada cultura. Es muy difícil encontrar estudios etnológicos que poder utilizar con propiedad como fuente de analogías con la Prehistoria, debido al desinterés mostrado en sus páginas por la cultura material, punto de contacto y de interés para el arqueólogo. De ahí que sea necesario desarrollar este tipo de análisis, hasta ahora inexistentes, y que sólo un investigador entrenado arqueológicamente disponga de la metodología adecuada para hacerlo.

Para continuar el argumento, debe hacerse siquiera una mínima alusión a las dificultades que han caracterizado las relaciones entre Antropología y Arqueología (en el sentido norteamericano del término, como disciplina que estudia el pasado). Como han señalado diversos autores (Leone, 1972: 16; Smith, 1976: 275-6; Gould, 1980: 2-3), la Arqueología no historicista se ha venido desarrollando como una disciplina «receptora» de las ideas y conocimientos generados en otra disciplina «donante», la Antropología. Los arqueólogos han seguido punto por punto los avatares de la discusión antropológica, en busca de sugerencias, leyes, ideas que poder aplicar al estudio del pasado. De hecho, dos de los textos clave para explicar el nacimiento de la Nueva Arqueología americana, que tantísima fuerza ha tenido y tiene en ese continente fueron "Archaeology as Anthropology" (Binford, 1962) y «Archaeology systematics and the study of culture process" (Binford, 1965), donde quedó claramente establecida la vinculación dependiente de la Arqueología respecto de la Antropología.

En este sentido, la Arqueología ha sido considerada, a menudo, como una disciplina secundaria, cuyo objetivo esencial, el estudio de la cultura material, podía complementar, como mucho, el conocimiento que de las culturas ofrecía la Antropología, pero que nunca ofrecería sus propios métodos y sistemas de análisis, que nunca sería autónoma. Los aspectos más interesantes del comportamiento humano sólo pueden aspirar a conocerse, a juicio de los antropólogos, a través del estudio de sociedades vivas, por lo que la Arqueología siempre ocuparía un lugar oscuro e irrelevante en el camino hacia dicho conocimiento. Además, paradójicamente, a medida que los arqueólogos se interesaban por el estudio de los procesos de cambio en el comportamiento humano del pasado, y no sólo de la cultura material, se hacían aún más dependientes de la Antropología, por lo que no parecía encontrarse solución a este dilema: o se queda- 
ban reducidos a meros cronistas de sucesos particulares del pasado, si mantenían su historicista alejamiento de la Antropología, o se veían obligados a utilizar información de segunda mano, elaborada por los antropólogos a partir de los etnólogos que trabajaban con las culturas vivas (Gould, 1980: 3).

Dados estos precedentes, puede ser más fácil entender el auge que determinados estudios etnológicos de campo realizados por arqueólogos tuvieron dentro de nuestra disciplina. Y, fundamentalmente, entender por qué estos estudios fueron llevados a cabo esencialmente en Estados Unidos, escenario de las competencias y conflictos entre ambas disciplinas.

En efecto, a partir de finales de los años $70 \mathrm{y}$ durante toda la década de los 80 , comienzan a proliferar en la bibliografía especializada detallados estudios etnográficos de sociedades vivas, contemporáneas, realizados bien por arqueólogos o bien por etnógrafos entrenados arqueológicamente (Gould, 1980: 3). Se trataba de un intento, por parte de los arqueólogos de superar las limitaciones inherentes a sus datos, sin que ello supusiera una dependencia paralela de las informaciones ofrecidas por la Antropología Social y Cultural. O, como tan acertadamente define Gould (1980: 3), se trataba del «desarrollo de un nuevo tipo de Antropología que está basado en las habilidades de observación e interpretación que son peculiares de la Arqueología». Esto es, por primera vez, los arqueólogos estaban planteando principios generales con los que conectar comportamiento humano y cultura material, obteniendo con ello conclusiones que, en absoluto, dependían del campo teórico de la Antropología, y que, sin embargo, podían complementar su conocimiento. La preocupación prioritaria de los arqueólogos por la cultura material estaba estimulando nuevas formas de registro etnológico (Gándara, 1990: 46).

A este tipo de estudios, consistentes en la obtención de información de primera mano sobre el comportamiento humano, mediante trabajo etnográfico realizado por arqueólogos se le ha llamado Etnoarqueología. Pero ¿se trata en realidad de Etnoarqueología? Es decir, ¿es Etnoarqueología el conjunto de principios, métodos y técnicas destinados a la obtención de información etnográfica con fines de razonamiento analógico en Prehistoria?

R.A. Gould (1968) inventó el término «Arqueología viva» («living archaeology») para designar ese tipo de estudio, al que se ha denominado también "etnografía arqueológica», "arqueoetnografía" y "arqueología de acción". Ahora bien, ¿,es correcto identificarlo con la Etnoarqueología, como parece pretender C. Kramer (1982: 1) en un brillante y famoso trabajo?

El mismo Gould (1974: 29; 1980: 3-4) se esfuerza en aclarar las diferencias que, a su juicio, lo separan de la Etnoarqueología: mientras esos estudios están referidos al trabajo de campo de un arqueólogo o etnógrafo en sociedades humanas vivas, "con especial referencia a la pauta de comportamiento "arqueológica" de esas sociedades", la Etnoarqueología se refiere a un marco general mucho más amplio, de comparación entre pautas etnográficas y arqueológicas. A su jucio, para desarrollar una investigación etnoarqueológica, el arqueólogo puede basarse en fuentes publicadas, de archivo, resultados experimentales o trabajo de campo. Es decir, la Etnoarqueología daría cabida a la "Arqueología viva», cuya principal característica es la obtención de información de primera mano en sociedades actuales, pero no viceversa.

A mi juicio, resultan acertadas las precisiones de Gould. Indudablemente, el término Etnoarqueología parece adaptarse etimológicamente al tipo de actividad que supone hacer Arqueología en grupos étnicos vivos - lo mismo que Etnografía arqueológica o Arqueoetnografía-. Desde este punto de vista, por tanto, no cabría objeción al uso del término. Ahora bien, de lo que se trata es de definir en qué consiste la Etnoarqueología en cuanto disciplina o metodología de estudio. Y en este sentido, la Etnoarqueología sólo cobró cuerpo, como señalaba antes, a raíz del desarrollo de la Nueva Arqueología. Por tanto, como metodología formada, la Etnoarqueología debe implicar, de algún modo, una relación entre los datos de las sociedades actuales y el conocimiento del pasado. La "Arqueología viva" no implica la segunda parte, por lo que, personalmente, sólo considero que se llega a convertir en Etnoarqueología cuando llega a esclarecerse la utilidad de la información que obtiene para el conocimiento del pasado. Para ello, obviamente, es necesario algún grado de generalización en las conclusiones que permita conectar culturas diferentes -en tiempo, espacio o en ambos-, por lo que no puede bastar hacer estudios arqueológicos particulares de culturas actuales para hacer Etnoarqueología. 
Como bien señalaba Gould (v. supra), la "Arqueología viva" puede ser parte de la Eınoarqueología, pero no necesariamente se identifica con ella.

\subsection{Etnoarqueología y Analogía Etnográfica}

Una de las confusiones más recurrentes en la bibliografía es la que se refiere a los contenidos, métodos y objetivos de la Etnoarqueología y de la analogía etnográfica.

A mi juicio, la Etnoarqueología y el uso de la analogía etnográfica son dos modos de aproximación al pasado prehistórico profundamente diferentes, por lo que su confusión sólo conduce a la descalificación de los resultados de una y otra cuando se intentan juzgar como lo mismo o a la obtención de resultados poco fiables cuando no se tienen claros sus respectivos niveles de generalización.

La analogía etnográfica forma parte inevitable del razonamiento arqueológico. No hubiéramos podido imaginar un pasado diferente de nuestro presente si no fuera por la evidencia de un presente también diferente; no hubiéramos atribuido funcionalidades o usos, y ni siquiera hubiéramos podido clasificar determinados objetos de no ser por la analogía etnográfica. La atribución de significados a objetos, estructuras, espacios, etc., su identificación, no hubiera podido realizarse sin ella.

Desde el comienzo de su Historia como disciplina, la Arqueología basó muchas de sus reconstrucciones en la analogía etnográfica. Como ya demostró Orme $(1974,1981)$, el impacto que el creciente conocimiento de otros pueblos había tenido en la sociedad occidental fue fundamental a la hora de poder plantear las primeras imágenes de la Prehistoria con una apariencia diferente a la del presente; por su parte, el reconocimiento de los mismos tipos de artefactos que los hallados en los yacimientos arqueológicos, en grupos vivos, permitió atribuirles un origen y una función ajenos ya a los míticos o mágicos, que en principio les fueron atribuídos (Wylie, 1985: 65). De hecho, Wilson (1851), Evans (1860) o las primeras interpretaciones del Arte Paleolítico hicieron depender con exclusividad de la analogía sus conclusiones (Yellen, 1977: 2), porque, sencillamente, no era posible reconstruir una imagen del pasado sin llenarla de imágenes del presente. Se explicite o no, toda reconstrucción del pasado es analógica en algún sentido. Ahora bien, ello no significa que pueda pensarse el pasado integrando indiscriminadamente retazos del presente, tal y como sucedió durante toda la primera parte de nuestro siglo (v. Wylie, 1985: 65-67 sobre los "primeros usos y abusos de la analogía»). Los excesos alcanzados llevaron a profundizar seriamente en el alcance y posibilidades de aplicación de la analogía como método de razonamiento en Arqueología (Wylie, 1985; Kent, 1987; Gándara, 1990) y recientemente, empiezan a precisarse sus límites con la Etnoarqueología (2).

Como bien señala Gándara (1990: 52), la argumentación por analogía es un "procedimiento que subyace en la expansión del conocimiento que caracteriza incluso a aplicaciones del sentido común»; y que se define por la «aplicación básica del procedimiento de inferencia inductiva, de proyección de lo conocido a lo desconocido». Es decir, la argumentación por analogía consiste en suponer que si tenemos dos contextos dados, que comparten determinadas características, podemos asumir que otra determinada característica, presente en el contexto fuente de la comparación, es también presumible en el contexto objeto de la analogía. Ahora bien, como sigue señalando dicho autor (Gándara, 1990: 55), no sólo se trata de comparar propiedades comunes, sino de poder establecer que éstas son más abundantes que las propiedades que ambos contextos no comparten; y además, es necesario establecer que las propiedades que comparten son relevantes.

Estas dos últimas condiciones han sido, precisamente, el centro de la discusión sobre la legitimidad del «enfoque histórico directo» basado en la aplicación de la llamada analogía «continua" (Gould, 1980: 35). Este tipo de analogía vincula, en una secuencia ininterrumpida estratigráficamente, los procesos culturales que intenta conocer/explicar/interpretar el arqueólogo, con los contextos de desarrollo de los actuales habitantes de la zona. Su definición se hace por oposición a la analogía «discontinua», que ofrece modelos de adaptación cultural observados en áreas muy lejanas en tiempo o espacio a las arqueológicas cuya interpretación se desea, pero con las mismas características ecológicas y ambientales (Gould, 1980: 34).

(2) Sirva de inmejorable ejemplo la comunicación «Ethnoarchaeology: what is it good for?", presentada por S. Kent al World Archaeological Congress-III, celebrado en Delhi, India, del 4 al 11 de diciembre de 1994. 
En general, se ha supuesto que la analogía "continua» ofrecía mucha mayor garantía de aplicabilidad que la "discontinua». Sin embargo, en diversos ámbitos (Gould, 1980: 35, por ejemplo) se ha cuestionado dicha convicción, dado que en todo caso, el contexto fuente que estamos utilizando es siempre una sociedad contemporánea. Y esto significa que cualquiera que sea el grupo o la zona donde se centre el análisis, pertenece, en general, a una órbita de actuación e influencia socio-política que puede haber transformado los parámetros más básicos que estructuran dicha sociedad, y por tanto, la relación de sus actividades con la cultura material que producen (v. el caso de Vogt y los indios mayas de los altos de Chiapas en Gándara, 1990: 55-56).

Se ha escrito mucho sobre aplicabilidad de la analogía entre rasgos de sociedades del presente y del pasado y en general, entre sociedades diferentes, bien en tiempo, bien en espacio. Desde cualquier posición teórica que podamos adoptar es necesario una base de semejanza que haga viable la comparación. Así, por ejemplo, desde una posición marxista (Gándara, 1990: 68) la viabilidad de la analogía está en función del grado de semejanza estructural que presenten el contexto fuente y aquel que se intenta conocer. Ahora bien, si tomamos al pie de la letra este principio, «nos quedamos inmediatamente sin análogos para la formación cazadora-recolectora, la formación tribal y la clasista inicial» (Gándara, 1990: 68). Ello, según Gándara, nos enfrenta a un serio dilema: por un lado, «si todo lo que podemos aprender sobre el pasado está en el presente, entonces no tiene mucho sentido estudiar el pasado; por otro lado, si para estudiar el pasado hemos de depender de la existencia de casos "legítimos" (esto es, históricamente comparables, homotaxiales), entonces hemos de aceptar que no existen análogos para muchos problemas de interés central. La analogía etnográfica sería irrelevante para la arqueología, porque la arqueología misma sería irrelevante» (Gándara, 1990: 69). Así pues, ¿tiene sentido, en la presente coyuntura de la disciplina, la aplicación de analogías etnográficas? Creo que la respuesta depende del tipo de conocimiento a que aspiremos a través de ella. Y la definición de éste viene ligada a la que demos a la cuestión que está guiando la elaboración de estas líneas: ¿es Etnoarqueología la analogía etnográfica? ¿Hacemos Etnoarqueología cuando compara- mos dos contextos históricos concretos, suponiendo que las características comunes son suficientes, y relevantes, y que por tanto, podemos asumir la presencia en el contexto más desconocido de otras características asociadas a las primeras en el contexto "visible"? ¿Tienen ambas el mismo objetivo de conocimiento?

Susan Kent (3) ha centrado en este punto una discusión reciente, que servirá de base para las puntualizaciones que, a modo de respuesta, podrían hacerse sobre estas cuestiones. Sin embargo, antes de desarrollarlas, convendría anticipar la crítica que, de seguro, puede hacerse a toda la argumentación que sigue, y que se deriva del hecho irrenunciable de que toda ella se sostiene sobre un paradigma procesual, positivista, ya que en él nació y se ha desarrollado la Etnoarqueología. Además, es dentro de este paradigma donde se confunden ambas heurísticas (la Arqueología post-procesual, por razones obvias, nunca aplicaría la analogía etnográfica), por lo que considero oportuno establecer desde ella sus diferencias. Más tarde (punto 3 ) tendremos oportunidad de precisar la idoneidad y operatividad de este tipo de asunciones.

Para delimitar las diferencias que pueden concebirse entre ambas, es preciso volver a recordar que la Etnoarqueología surgió con el desarrollo de la Nueva Arqueología como una de sus Teorías de Alcance Medio. Así pues, por pura definición, puede empezar por señalarse que:

$\left.1^{\circ}\right)$ Mientras la analogía etnográfica establece semejanzas entre casos particulares, la Etnoarqueología hace generalizaciones que aspiran a tener rango de ley. Esto quiere decir que mientras la analogía etnográfica compara casos etnográficos particulares con casos arqueológicos particulares, la etnoarqueología busca la generalización: su objetivo es llegar a comprender bajo qué circunstancias puede esperarse un cierto tipo de comportamiento o la aparición de un cierto registro material (Gilman, 1987: 540). Para ello, necesita construir modelos de comportamiento derivados de estudios etnográficos comparativos que garanticen que dichos modelos no están vinculados a un período o cultura particular (4).

(3) V. nota (2).

(4) V. nota (2), pág. 9 del trabajo original.

T. P., 52, n. $^{\circ} 2,1995$ 
$\left.2^{\circ}\right)$ Es decir, la analogía etnográfica establece comparaciones puntuales entre dos culturas - del presente y del pasado- concretas. La etnoarqueología, en cambio, revisa la variabilidad presente en el registro etnográfico respecto a un cierto comportamiento, proceso de cambio, etc. Si de la contrastación del modelo propuesto en los casos revisados puede derivarse alguna regla general aplicable a todos ellos, podrá entonces presumirse que dicha regla será aplicable también a las culturas del pasado. Es decir, «una vez que un modelo se ha validado en distintas culturas y los factores que influyen en la variabilidad del modelo han sido comprendidos. puede considerarse apropiado para su aplicación a los datos arqueológicos, que no sólo son de una cultura diferente, sino además, de un tiempo diferente» (5).

$3^{\circ}$ ) Esto nos lleva a una distinción más entre analogía etnográfica y etnoarqueología: la primera extrapola los términos bajo comparación de sus respectivos contextos culturales. Es decir, establece identidades de funcionamiento, uso, etc., entre elementos que pertenecen a culturas muy alejadas en tiempo o espacio, sin prestar mayor consideración a las diferencias del resto de las características culturales. Sin embargo, la principal preocupación de la etnoarqueología es exactamente la opuesta: llegar a comprender en qué contextos culturales, bajo qué condiciones socio-económicas, ideológicas o ambientales, puede aparecer un determinado modelo de comportamiento. Lo que nos lleva a que:

$4^{\circ}$ ) La analogía etnográfica se ocupa de los elementos que integran la cultura, mientras que la etnoarqueología está preocupada por los contextos culturales (6). O lo que es lo mismo:

$\left.5^{\circ}\right)$ La analogía etnográfica es descriptiva: identifica el uso, función, relación con, etc., de objetos, estructuras, espacios, áreas de actividad, etc.; la etnoarqueología, en cambio, es explicativa/interpretativa: intenta comprender qué condiciones deben darse en una cultura para que aparezcan determinados rasgos en su cultura material.

$6^{\circ}$ ) La etnoarqueología tiene como resultado la obtención de generalizaciones en forma de

(5) V. nota (2), pág. 7 del trabajo original.

(6) V. nota (2). ley. o de proposiciones generales (v. infra) que pueden aplicarse no sólo a culturas del pasado. sino también del presente. Es decir, establece contextos de funcionamiento, causas o significados similares en culturas diferentes; si la diferencia reside en el tiempo o en el espacio resulta irrelevante.

Así pues, todas estas condiciones debieran permitir diferenciar estudios etnoarqueológicos sensu strictu de estudios de analogía etnográfica preocupados por obtener mediante trabajo directo de campo ("arqueología viva») datos de primera mano que poder aplicar a un caso particular del pasado. Como claramente se establece, la diferencia no radica sólo en estudiar uno o más casos particulares, sino en el tipo de información que se busca y en el grado de generalización que ésa permite. Así pues, aunque la laxitud con que se ha empleado el término Etnoarqueología ha permitido acoger estudios de analogía etnográfica, ambas heurísticas, útiles y lícitas para el conocimiento de las culturas del pasado, tienen, sensu strictu contenidos, objetivos y alcances diferentes.

\section{3. ¿Qué ámbito cultural estudia la Etnoar- queología?}

Como hemos visto, el enfoque procesual, iniciado con la Nueva Arqueología liderada por L.R. Binford, y el post-procesual, a cuya cabeza encontramos a I. Hodder, han defendido posiciones diametralmente opuestas en relación a la Etnoarqueología. Mientras los primeros buscaban generalizaciones en forma de ley que poder aplicar a distintas culturas, los segundos negaban siquiera su posibilidad, dado que lo relevante de una cultura es el código de significados particulares que constituye la clave de su funcionamiento.

De una manera sintética, puede resumirse la oposición entre ambas a través de los siguientes rasgos (David, 1992: 334): 1) uso preferencial, por parte de los procesuales, de enfoques cuantitativos y de la inferencia estadística, dado el positivismo que les define. Como sabemos, la Nueva Arqueología pretendía adoptar los métodos y técnicas de las Ciencias Naturales como los únicos que podían garantizar la objetividad del conocimiento; 2 ) un interés por conocer el comportamiento de los grupos humanos de los primeros, frente al interés de los postprocesuales por el significado oculto de ese 
comportamiento; 3 ) un énfasis de los primeros en el contexto de la justificación de una hipótesis sobre el del descubrimiento, que caracterizaba a los segundos. De hecho, para Binford (1968: 18), la analogía sólo era el punto de partida de una hipótesis que habría de ser independientemente evaluada (Gándara, 1990: 75), lo que garantizaba la objetividad de las conclusiones finales, sin depender del origen o carácter de la analogía (v. Wylie, 1985: 85-88 y Fernández Martínez, 1994: 161 sobre el desarrollo y la transformación posterior de este planteamiento inicial). El argumento era compartido por los marxistas para quienes, "a fin de cuentas, si somos materialistas, la palabra final la tiene la realidad" (Gándara, 1990: 67). Sin embargo, desde la Arqueología Contextual la hipótesis sobre el significado de los códigos que se manifiestan en la cultura material sólo puede derivarse del conocimiento interno de una cultura, por lo que es el planteamiento de la hipótesis la única y total aspiración del etnoarqueólogo; 4) un énfasis de los procesuales en la deducción, como consecuente derivación de la aspiración a asemejarse en sus métodos a los de las Ciencias Naturales, frente al énfasis en la inducción de los post-procesuales. Para éstos, la particularidad del funcionamiento de los códigos de significado en cada cultura, obliga a un procedimiento de inferencia inductiva para conocerlos; y 5) la confianza que los primeros depositan en la existencia de leyes trans-culturales que puedan explicar determinados aspectos culturales - en el caso de la Etnoarqueología las que dan cuenta de la relación entre cultura material y comportamiento humano-. En contra, el interés de los segundos por el estudio de lo que denominan la «pauta cultural» que define a cada grupo humano, en la suposición de que consiste en relaciones de significado que se manifiestan en cada una de las expresiones culturales de un modo particular y no generalizable a ningún otro.

Pero las diferencias que existen entre ambas van más allá, pues están referidas al ámbito de la cultura por el que cada una de ellas se interesa. La escuela procesual únicamente tiene en consideración lo que Goodenough (1964) definió como el "Orden Fenomenológico" de la Cultura, que estaría integrado por las «actividades», pautas de comportamiento, etc., vinculadas a las esferas tecnológica, social o ideológica, y manifestadas a través de la cultura material
(David, 1992: 335) (Fig. 1)(7). El interés de la etnoarqueología procesual es establecer regularidades en forma de ley que expliquen la formación de ese registro material a partir del Orden Fenomenológico que lo ha creado. Es decir, su objetivo es establecer la relación entre el dinámico comportamiento humano y el estático

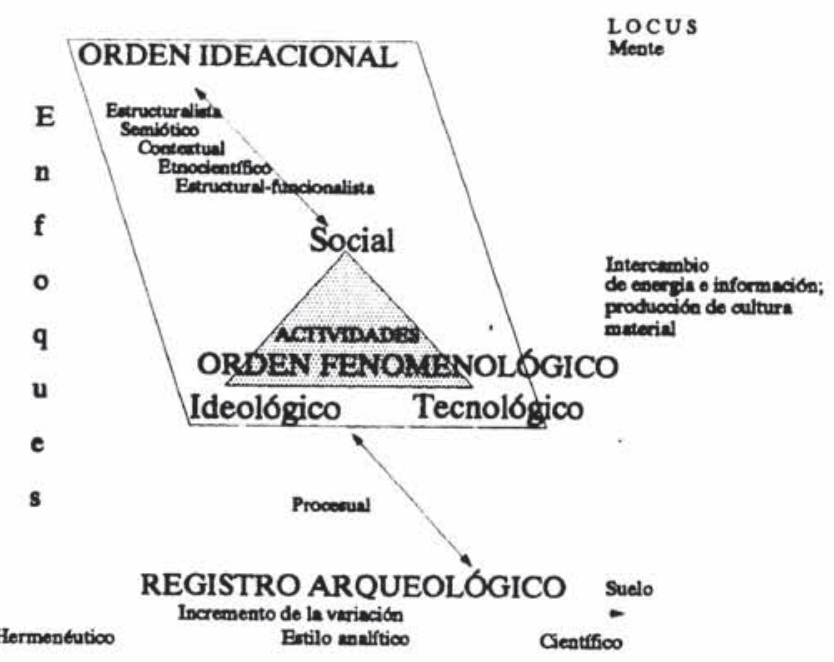

Fig. 1. Los dominios culturales y su relación con los enfoques interpretativos y los estilos analíticos, según David (1992).

registro arqueológico: qué tipos de comportamientos y actividades pueden haber originado determinadas funciones, usos, dispersión o asociaciones de elementos materiales. En un principio, los procesuales aspiraron a poder encontrar leyes_que pudieran «prescribir la naturaleza funcional de los fenómenos» (Stickel y Chartkoff, 1973: 665 en Gould, 1980: 41), lo que es igual a leyes de dependencia funcional en las que no tenía cabida el factor tiempo. Consideraban que el objetivo de la arqueología era descubrir las pautas y tendencias generales del comportamiento humano, en lugar de preocuparse por historias particulares de individuos o comunidades (Gould, 1980: 41). Numerosas voces se levantaron frente a semejante declaración de principios, arguyendo la implicación de

(7) Mi agradecimiento a Ramón Herrero y $\mathrm{M}^{\mathrm{a}}$ Dolores Portero por la elaboración de esta figura. 
la Arqueología con la totalidad del comportamiento representado en los restos que estudia. A consecuencia de ello. se propuso sustituir la búsqueda de "leyes" generales de comportamiento por la de "proposiciones" de distinta indole que dieran cuenta de los distintos comportamientos observables en el pasado (Gould. 1980: 41). Como resultado. la etnoarqueología pasó a definirse como la disciplina que «intenta observar relaciones entre los requerimientos esenciales para sostener la vida humana en unas situaciones dadas y las formas en que la gente se comporta en respuesta a esos requerimientos" (Gould, 1980: 43). La explícita declaración de Gould (1980: 43) no deja lugar a dudas: como etnoarqueólogos, nuestro objetivo principal es "comprender la naturaleza esencial de estas relaciones, y no descubrir una "cosa" denominada cultura o incluso culturas particulares".

El problema de este planteamiento es que, necesariamente, presenta conclusiones de alcance reducido, afectando esencialmente a comportamientos técnicos o sociales (David, 1992: 351). Además, el tipo de conclusiones que alcanzaban fueron ridiculizadas por muchos, al considerarlas de un nivel tan amplio de generalización, que no resultaban informativas.

Sin embargo, la cultura no estaría integrada sólo por dicho nivel de actuación de las estructuras, sino también por aquel otro donde éstas se definen, lo que Goodenough (1964) llamó el Orden Ideacional. Éste estaría integrado por las ideas, valores, normas y representaciones que sirven de materia básica para la construcción del orden cultural (David, 1992: 334). Es decir, constituiría el patrón de racionalidad de cada sociedad, la definición de los parámetros esenciales de identidad de un grupo social. Este Orden Ideacional no puede pensarse, en modo alguno, aislado o previo al Orden Fenomenológico de la Cultura. Su definición no puede concebirse sino en una relación de estrecha interrelación con éste, de manera que sólo a través del conoci- . miento de uno puede entenderse el otro y viceversa. A su vez, sólo entendiendo ambos como parte de un conjunto más amplio integrado por el medio en el que se desarrolla esa cultura y las relaciones que se establecen con otros órdenes culturales podremos dar cuenta de sus respectivas características (Fig. 1) (David, 1992: 334).

Así pues, sólo entendiendo las relaciones entre ambos órdenes podremos entender el comportamiento de una determinada sociedad, y en consecuencia la cultura material que de ése se deriva. Desde este punto de vista, pierde sentido la aproximación procesual a la Etnoarqueología, donde se intenta conectar registro arqueológico con comportamientos socio-tecnológicos generalizables a lo largo del tiempo y del espacio. Sin embargo, lo mismo sucede con la aproximación protagonizada por la escuela post-procesual que, con I. Hodder a la cabeza, propuso una Etnoarqueología dedicada a desvelar los códigos de significado ocultos en la cultura material. Es decir, la conexión volvía a demostrarse insuficiente, ya que únicamente se establecía entre la cultura material y el orden ideacional, sin prestar al orden fenomenológico de la cultura más atención que la necesaria para desvelar aquél. La Etnoarqueología se convertía así en una disciplina de objetivos exclusivamente particularistas, cuyas conclusiones sólo aspiraban a comprender la estructura que informaba la cultura en la que se estaba trabajando, a descubrir las normas e ideas que definían, individualizando, a cada grupo humano. Como muchas de sus propuestas (Ruiz et alii, 1988: 15), su aplicación sólo tenía sentido en el presente, con grupos vivos; pero dada su negación del «uniformismo" y la desaparición de las sociedades del pasado, resulta verdaderamente difícil imaginar la contribución concreta que podría aportar a los estudios prehistóricos.

\section{UNA ETNOARQUEOLOGÍA ALTER- NATIVA}

Puestas así las cosas, dadas las decepciones que tanto los planteamientos procesuales como los post-procesuales han provocado a sus propios defensores, y dado el clima de cierta insatisfacción que, como decíamos al principio, parece respirarse hoy en la Prehistoria europea, ¿qué sentido puede tener hoy hacer Etnoarqueología?

A mi juicio, puede suponer una vía de salida a la presente situación, ofreciendo una atractiva alternativa para seguir profundizando en el conocimiento del pasado. Pero para ello, el énfasis debe situarse en la relación entre el orden ideacional y el orden fenomenológico de la cultura, en lugar de enfocar el análisis de cualquiera de ellos por separado. Quiero decir, que sólo entendiendo la profunda interrelación entre pautas de racionalidad y orden social podremos 
entender las pautas observables de la cultura material que esa sociedad produce. En este sentido, como bien apunta David (1992: 351), «la etnoarqueología se está haciendo menos restringida a los tópicos de interés arqueológico específico e inmediato».

Creo que la Etnoarqueología puede ofrecernos referencias que sirvan para ir construyendo un marco de comprensión general de una cultura. Puede señalarnos qué tipo de racionalidad debió estar presente para que se formara determinado registro material; o al menos, indicarnos qué pautas de racionalidad no pudieron estar presentes y por tanto, cómo no debe pensarse en determinados comportamientos -ideológicos, sociales, tecnológicos- como agentes de dicho registro.

Para ilustrar el alcance de la información que creo puede obtenerse desde este nuevo planteamiento, utilizaré un caso de estudio particular, limitándome a esbozar el planteamiento que lo sustenta dado el estado preliminar del trabajo (8).

\section{UN CASO DE ESTUDIO}

Como todos sabemos, el Neolítico europeo fue una fase histórica caracterizada por cambios trascendentales en la cultura. Tradicionalmente éstos se identificaron con la aparición de determinados restos materiales: las especies domésticas, la cerámica o la piedra pulimentada. Sin embargo, hace tiempo que se viene señalando (Hernando, 1994) que esta aparición no trajo aparejada una transformación relevante del orden cultural. Éste sólo se habría producido al final del Neolítico, cuando hacen su aparición las aldeas, las necrópolis o una tecnología más especializada, indicadores, todos ellos, de un patrón de racionalidad diferente (Criado, 1989; Criado, 1993: 40; Vicent, 1990).

Pero si el registro material presenta esta transformación es porque el binomio orden ideacional-fenomenológico es también distinto, porque se han alterado las pautas básicas de funcionamiento de la cultura, tendentes ahora a un mayor nivel de complejidad: «surgimiento de

(8) Financiado gracias a la concesión de un Proyecto a Grupos Precompetitivos (PR19/94-5375/94) de la Universidad Complutense de Madrid, bajo el título: «Pautas de poblamiento y ocupación del territorio en el área kekchí de Chahal (Alta Verapaz, Guatemala)». la tecnología como esfera especializada de actividad (...), aparición de racionalidades económicas maximizadoras de la productividad, emergencia de formas monumentales de expresión del poder, despuntar de las primeras imágenes del tiempo como base de la tradición y la memoria social" (Criado, 1993: 40).

Y esta transformación de las pautas de racionalidad y de las actividades de una cultura se produce de manera simultánea y esencialmente similar en gran parte de Europa, como nos han demostrado las secuencias particulares de desarrollo tan detalladamente reconstruidas en la mayor parte de su territorio. Personalmente, considero prioritario investigar las claves de dicha transformación, si queremos comprender después las características particulares que luego revestirá la cultura en cada uno de los casos.

Para ello, he fijado la atención en dos parámetros esenciales para la construcción de cualquier orden cultural: la percepción del tiempo y el espacio y su transformación desde las sociedades cazadoras a las posteriores sociedades complejas. Se ha dicho (Kern, 1983: 5) que «a través de la interpretación de la cultura como una función del tiempo y el espacio, se hace posible comparar diferentes edades y distintas culturas». En efecto, ambos constituyen coordenadas fundamentales en la definición de una cultura, marcos intrínsecamente relacionados con el contenido más concreto de cada una de las realidades culturales. De hecho, no es posible el concepto de movimiento sin la categoría «tiempo», por lo que el tiempo es una variable necesaria del cambio social (Sorokin y Merton, 1990: 56). Hayamos o no prestado atención a semejante variable, es parte inevitable de cada construcción cultural.

Pero, a su vez, cada modalidad de percepción del tiempo lleva aparejada una determinada del espacio, por lo que sólo comprendiendo ambas podremos llegar a vislumbrar el esquema básico de actuación sobre el paisaje y el ordenamiento social que se expresa en la cultura material de los yacimientos que excavamos.

En fechas recientes se está desarrollando un tipo de aproximación al pasado, la llamada «Arqueología del Paisaje» (Tilley, 1994; Criado, 1993 y e.p.) que intenta reconocer la racionalidad espacial (no sólo en dimensión material del paisaje social, sino también en la ideal o imaginaria) de los paisajes prehistóricos (Criado, 1993: 42). Sin embargo, mientras la percepción 
que un grupo humano tiene del espacio parece objetivable a través de la disposición. visibilidad. carácter, etc. de los elementos que lo integran. resulta difícil imaginar cómo puede investigarse la percepción que dicho grupo tenía del tiempo, y, sobre todo, en qué medida dicha percepción puede resultar relevante para comprender el comportamiento, proceso de cambio, etc., del grupo bajo análisis.

Sin embargo, considero que el intento de averiguar cuáles son las pautas de racionalidad basadas en los parámetros tiempo-espacio que se asocian a una economía de caza-recolección, a una economía de agricultura de subsistencia y a una economía maximizadora de beneficios, puede constituir una vía enormemente fructífera en la profundización de las claves fundamentales del cambio que se produce en el Neolítico. Mi objetivo, por tanto, consiste en desvelar las pautas de racionalidad esencial que se asocian a cada tipo de construcción social y a su racionalidad económica, esto es, a su Orden Fenomenológico en palabras de Goodenough.

No pretendo establecer analogías entre grupos actuales y determinadas fases de la Prehistoria, sino llegar a averiguar cuáles son las pautas comunes que permiten y a la vez son resultado de, en una interrelación retroalimentada, la existencia de cada una de las modalidades de relacionarse con el entorno que el hombre ha sido capaz de desarrollar. En este sentido, el objetivo de mi búsqueda son proposiciones generales sobre la relación entre el Orden Fenomenológico y el Orden Ideacional de la cultura que, por poder generalizarse en los diferentes grupos vivos que paulatinamente irán siendo objeto de análisis, sean igualmente de aplicación a los que protagonizaron la Prehistoria.

Para comenzar el análisis he elegido a los kekchíes, un grupo de agricultores de subsistencia que habitan en las montañas que rodean el municipio de Chahal, Departamento de Alta Verapaz, Guatemala (Fig. 2).

La estructura de organización de los Kekchíes está perfectamente definida, a través de lo que E. Wolf $(1955,1968,1982)$ llamó una «comunidad corporativa cerrada", que, a su juicio, constituye uno de los dos tipos principales de formaciones campesinas de Latinoamérica. Esta forma de organización podría definirse (Wolf, 1955: 456-461) por establecerse en tierras marginales, usar tecnología tradicional, mantener el grado de pobreza necesaria para preservar el orden cultural tradicional (hasta el punto de poder definirse un "culto a la pobreza"), la jurisdicción comunal sobre el libre uso de la tierra, un sistema político-religioso que define los límites de la comunidad y es el símbolo de la unidad colectiva, un rechazo activo de la posibilidad de encontrar alternativas culturales que pudieran transformar su orden cultural y la familia nuclear como base del sistema.

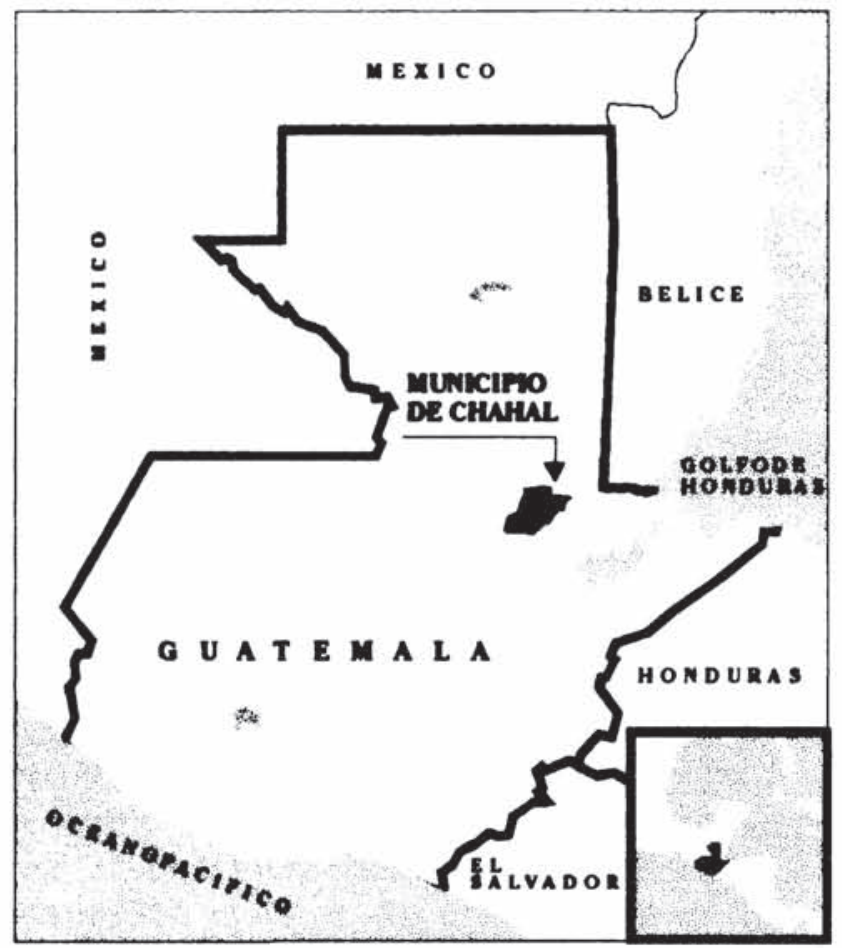

Fig. 2. Mapa de Guatemala con indicación de la zona de estudio.

El mantenimiento del orden tradicional, del orden interno de la comunidad, es el objetivo absolutamente prioritario del kekchí. Y éste viene dado, en esencia, por su vinculación al sistema de cultivo de la milpa, que vertebra las categorías de tiempo y espacio, la cosmogonía kekchí (Medina, 1990: 457). Así pues, mantener el orden interno y, en definitiva, sobrevivir con identidad cultural propia, deriva del mantenimiento del modo productivo. Éste no ha cambiado en los últimos tres mil años: consiste en lo que se ha llamado agricultura de rozas, tala y quema o cultivo de «milpa» en Mesoamérica. Se caracteriza por a) utilizar exclusivamente hombres y animales, y no energías producidas por combustibles o elementos artificiales; b) largos 
períodos de barbecho - entre 4 y 6 años-y utilización del fuego para clarear y preparar para el cultivo las parcelas (Pacheco, 1985: 57): c) el palo cavador o vara de sembrar, el hacha de piedra y la bolsa de fibra para llevar la semilla se mantienen a lo largo del tiempo, aunque en algunos lugares han agregado el cuchillo, el hacha de metal y el azadón (Pacheco, 1985: 57). Ni arado, ni tracción animal, ni abono químico, ni ningún otro medio de intensificación económica han entrado nunca en estas tierras.

El caso kekchí puede parecer alejado como contexto-fuente para extraer información útil a la Prehistoria europea. Habitan una zona montañosa, entre las Sierra de Chamá y Santa Cruz, las últimas estribaciones de la Cordillera de los Cuchumatanes, con una media pluviométrica entre 2.300 y $3.800 \mathrm{~mm}$. (Arnauld, 1986: 24) y una altitud media superior a los $2.000 \mathrm{mts}$., decreciendo lentamente a medida que descienden a la selva del Petén.

Y ciertamente lo sería si lo que estuviéramos tratando de hacer fuera aplicar una analogía etnográfica. No presentan similitud étnica, como querría un «enfoque histórico directo», ni ecológica, como necesitaría cualquier investigador procesual. Pero, sin embargo, no creo que ambas condiciones sean necesarias para desarrollar un estudio etnoarqueológico útil. Porque, como hemos ido viendo, allí donde la Analogía describe, identifica y compara, la Etnoarqueología interpreta, contextualiza y sugiere.

En este sentido, el conocimiento de la percepción del tiempo y el espacio por parte de los kekchíes puede servir de inicio a la investigación de las pautas de racionalidad que se asocian a una agricultura de subsistencia, de roza y quema, como las que debieron desarrollarse en las primeras fases neolíticas europeas. De ellas pueden derivarse sugerencias sobre la lógica de actuación sobre el paisaje y en las relaciones socio-económicas que nos sería imposible pensar desde Europa.

La percepción del tiempo entre los kekchíes coincide, en sus rasgos esenciales, con la detectada por Bourdieu (1990) para los Kabyle de Argelia. Ambos siguen manteniendo una actitud de dependencia y solidaridad hacia la Naturaleza, de la que aún, como los cazadores, se consideran parte. Y esta posición conflictiva y contradictoria, en la que el agricultor se ve obligado a actuar sobre la naturaleza, ejerciendo sobre ella algún tipo de violencia, para de esa manera fecundarla y sobrevivir, se asocia a una percepción determinada del tiempo, que puede servir de guía para comprender su racionalidad. La tierra no es un medio de producción de naturaleza ajena a la del agricultor, sino que éste se considera aún parte de ella, sometido a sus ritmos. Su sentido del tiempo, por tanto, está muy vinculado a su sometimiento a la naturaleza.

Tanto para los kabyle como para los kekchíes, el lapso de tiempo que constituye el presente abarca una unidad de percepción que incluye el pasado inmediato y el futuro que puede anticiparse por estar estrechamente vinculado a él. Todo ello pertenece a un mismo horizonte de significado, que a su vez, se asocia a la experiencia de actividad y al espacio en que ésta tiene lugar: la duración y el espacio no son pensables si no es desde la referencia que da la realización de alguna tarea concreta (Bourdieu, 1990: 2234). Ello refuerza la vinculación al suelo, base de su estructura social, que de esta manera sustituye al parentesco, garantizando, mediante mitos y atribuciones de identidad a cada uno de los elementos del paisaje, la permanencia y supervivencia del grupo.

No contemplan un futuro como el nuestro. Pueden planear la cosecha y el ciclo agrícola siguiente, pero siempre como un modo de anticipación del mismo presente vivido, de repetición insaciable de los ritmos conocidos. Mientras nuestra sociedad se caracteriza por el constante cambio, el deseo perpetuo de transformación, la suya lo hace por la repetición, el desesperado deseo de permanencia de lo mismo. No tienen la posibilidad de plantear un futuro diferente al presente. Es decir, para ellos el futuro no es un conjunto de posibilidades, tan amplio como la imaginación sea capaz de concebir. Para ellos, el futuro debe ser de una determinada manera, la manera del presente, aquélla que ha garantizado la supervivencia hasta el momento. Cualquier otra posibilidad entraña riesgo, y por tanto, se descarta. Al contrario que nosotros, que aspiramos a construir un presente a la medida del futuro que imaginamos, ellos aspiran a construir un futuro a la medida del presente que conocen.

Por ello, mientras nuestra sociedad valora el cambio como la clave del funcionamiento social y personal y, por tanto, como lo deseable y positivo, la suya no contempla el cambio como parte del sistema. Las escasas alusiones a cambios tie- 
nen siempre su referencia en otra lógica, inmersa en el mundo mítico con el que tan estrechamente se relaciona la realidad percibida (Bourdieu, 1990). Siempre se identifica con castigo, sin que parta nunca de una motivación personal ni pueda asociarse a consecuencias positivas. Por ejemplo, los kekchíes atribuyen el agotamiento de sus tierras y el menor rendimiento de sus cosechas al enfado de Tzultzaká, el dios del Cerro. Éste, en castigo por la relajación de los rituales tradicionales por parte de los más jóvenes, les está retirando las cosechas, los animales salvajes que antes podían cazar, etc., etc..

De todo ello se deriva que mientras nuestro pensamiento se caracteriza por la capacidad de abstracción, de imaginación de posibilidades no experimentadas, el suyo es un pensamiento mucho más concreto, vinculándose en su necesidad de fantasía al mundo mítico, el cual, por su parte, se define, como todos sabemos, por el estatismo y la falta de referencia al tiempo.

Una mentalidad como la de los kekchíes se relaciona estructuralmente con una economía de rendimientos no-diferidos, donde todo el ciclo productivo pueda contemplarse como una misma unidad de acción. Es decir, un ciclo en el que el productor no separe el presente que es el trabajo, del futuro que son sus resultados económicos (Bourdieu, 1990: 230), bien porque el ciclo sea inmediato o corto, o bien porque los resultados puedan anticiparse por la ausencia de variables de cambio. Ésta es la situación en la que se encuentran los grupos cazadores-recolectores y los primeros horticultores y agricultores de rozas, como los kekchíes. Pero el sistema se refuerza a sí mismo. Es decir, ninguno de ellos puede concebir el cambio, luego ninguno lo introducirá si son capaces de evitarlo. No podemos olvidarnos de esto a la hora de pensar en las lógicas de actuación de las distintas sociedades de la Prehistoria.

Como señalaba algunos párrafos atrás, he querido utilizar este caso a modo de ejemplo de lo que, personalmente, considero puede ser una de las aportaciones que la Etnoarqueología pueda ofrecer al estudio de la Prehistoria europea. El estado preliminar de mi trabajo impide, sin embargo, desarrollos más amplios que los consistentes en demostrar qué vías de aproximación al pasado pueden abrirse utilizando metodologías y heurísticas diferentes a las tradicionales.
Las sociedades del Neolítico Antiguo y Medio, a juzgar por la información arqueológica de que disponemos, debieron caracterizarse por estrategias agrícolas semejantes a las utilizadas por los kekchíes o los kabyle. Sería impensable establecer una analogía "discontinua" entre ellos y nuestro pasado. No podemos olvidar que su forma de organización y relación con el medio es el resultado de muchos años y mucha Historia, y que su estructura socio-económica actual es "contemporánea", es una forma de supervivencia hoy, y no un reducto prístino del pasado. Sin embargo, su estrategia económica tiene que tener un correlato en el Orden Ideacional, sin el cual no podría mantenerse y éste está definido por unas ciertas coordenadas espacio-tiempo. Creo que está relación puede demostrarse sostenida para niveles de complejidad socio-económica dados.

En este sentido, creo que la Etnoarqueología, entendida como disciplina que aspira a comprender esta relación, y a ponerla en conexión después con las expresiones materiales básicas de cada una de ellas, puede ofrecernos un marco de pensamiento de enorme valor para entender las culturas de la Prehistoria.

No se trata de comparar culturas, sino de comprender otros órdenes de pensamiento, otras formas de identidad personal y cultural. Me parece necesario conocer otras lógicas de actuación diferentes a la occidental-capitalista que guía nuestro pensamiento. Y para ello, no basta con leer literatura antropológica, con realizar trabajo de campo etnológico. Es necesario establecer correlaciones que se mantengan en diversos grupos del presente, para poder presumir que podrían haber estado igualmente presentes en los grupos del pasado. Y sobre todo, encontrar qué relación existe entre ellas y el registro material concreto, qué tipo de regularidades corresponden a cada forma de racionalidad. Por ejemplo, qué significa la dependencia de la naturaleza a efectos de modalidades de hábitats, enterramientos, almacenamiento, vinculación a un «territorio», conflictos territoriales, demarcadores territoriales, amplitud de los desplazamientos, etc., etc., etc..

Creo que faltan por hacer preguntas previas a las que ya nos hemos hecho en Prehistoria; que faltan respuestas que servirían para orientar futuras preguntas concretas al registro arqueológico; y que la Etnoarqueología puede ser una vía eficaz para sugerirlas. 


\section{BIBLIOGRAFÍA}

Arnaul.d. M. Ch. (1986): Archéologie de I'habitat en Alta Verapaz (Guatemala). Études Mesoamericaines X. Centre d’études mexicaines et centramericaines. México.

BINFORD, R.L. (1962): "Archaeology as anthropology", American Antiquity, 28: 217-225.

- (1965): "Archaeological systematics and the study of culture process». American Antiquity, 31: 203-210.

- (1967): "Smudge pits and hide smoking: the use of analogy in archaeological reasoning". American Antiquity. 32: $1-12$.

- (1978): "Nunamiut Ethnoarchaeology". Academic Press. New York.

Bourdieu, P. (1990): "Time Perspectives of the Kabyle". En J. Hassard (ed.): "The Sociology of Time». St. Martin's Press, New York: 219-237.

Criado Boado, F. (1989): "Tiempos megalíticos y espacios modernos». Historia y Critica. I: 85-108.

- (1993): “Visibilidad e interpretación del registro arqueológico». Trabajos de Prehistoria, 50: 39- 56.

- (e.p.): «Límites y posibilidades de la Arqueología del Paisaje». SPAL, 2.

DAvID, N. (1992) «Integrating Ethnoarchaeology: A Subtle Realist Perspective». Journal of Anthropological Archaeology, 11: 330-359.

DEAL, M. (1985): «Household pottery disposal in the Maya Highlands: an ethnoarchaeological interpretation". Journal of Anthropological Archaeology, 4: 243-291.

Evans, J. (1860): "Reigate flints». Proceedings of the Society of Antiquaries. January 1860.

FERNÁNDEZ MARTíNEZ, V. (1994): «Etnoarqueología: una guía de métodos y aplicaciones». Revista de Dialectologia y Tradiciones Populares, XLIX: 138-169.

GÁNDARA, M. (1990): «La Analogía Etnográfica como Heurística: Lógica Muestreal, Dominios Ontológicos e Historicidad». En Y. Sugiura Y. y M.C. Serra P. (eds.): "Etnoarqueología. Coloquio Bosch-Gimpera". Instituto de Investigaciones Antropológicas. Universidad Nacional Autónoma de México. México: 43-82.

GiLmAN, P. (1987): «Architecture as Artifact: pit structures and pueblos in the American Southwest". American Antiquity, 52(3): 538-564.

GoODENOUGH, W.H. (1964): «Introduction». En W.H. Goodenough (ed.): "Explorations in cultural anthropology». McGraw-Hill, New York: 1-24.

GoulD, R.A. (1968): «Living archaeology: The Ngatatjara of Western Australia». Southwestern Journal of Anthropology, 24: 101-122.

- (1974): «Some current problems in Ethnoarchaeology». En C.W. Clewlow, Jr. (ed.): «Ethnoarchaeology». Monograph IV. Archaeological Survey. Institute of Archaeology, University of California. Los Angeles: 29-47.

- (1980): "Living Archaeology». New Studies in Archaeology. Cambridge University Press. Cambridge.

HAYdEN, B. y CANNON, A. (1983): «Where the garbage goes: Refuse disposal in the Maya Highlands». Journal of Anthropological Archaeology, 2: 117-163.
- (1984): "The Structure of Material Systems: Ethmoarchaeolgy in the Maya Highlands.. Society for American Archaeology. Washington.

Hernanido. A. (1994): "El proceso de Neolitización. Perspectivas actuales para el estudio del Neolíticom. Zephyrus. XLVI: 12.3-142.

HODDER. I. (1988): "Interpretacion en Arqueologia. Corrientes actuales". Ed. Crítica. Barcelona.

KENT, S. (1987): "Parts as wholes: A critique of theory in archaeology". En S. Kent (ed.): "Method and theory for activity area research: an ethnoarchaeological approachp. Columbia University Press. New York: 513-547.

KERN, S. (1983): "The Culture of Time and Space. 18801918». Harvard University Press. Cambridge, Massachusetts.

KRAMER, C. (1982): “Village Ethnoarchaeology. Rural Iran in archaeological perspective». Academic Press. New York.

LEE, R.B. y DE VORE, I. (eds.) (1968): "Man the hunter». Aldine. Chicago.

- (1976): "Kalahari hunters and gatherers». Harvard University Press. Cambridge.

LEONE, M.P. (1972): «Issues in anthropological archaeology». En M.P. Leone (ed.): "Contemporary archaeology». Southern Illinois University Press. Carbondale: 14-27.

MedinA, A. (1990): «Arqueología y etnografía en el desarrollo histórico mesoamericano». En Y. Sugiura Y. y M.C. Serra P. (eds.): "Etnoarqueología. Coloquio Bosch Gimpera». Instituto de Investigaciones Antropológicas, Universidad Nacional Autónoma de México, México: 447-481.

Orme, B. (1974): «Twentieth-century prehistorians and the idea of ethnographic parallels». Man, N.S., 9: 199-212.

- (1981): "Anthropology for archaeologists: An introduction». Cornell University Press. Ithaca, New York.

OSWALT, W.H. (1974): «Ethnoarchaeology». En C.W. Clewlow, Jr. (ed.): "Ethnoarchaeology». Monograph IV. Archaeological Survey. Institute of Archaeology. University of California. Los Angeles: 3-26.

PACHECO, L. (1985): "Religiosidad maya-kekchí alrededor del maíz». Ed. Escuela Para Todos. San José, Costa Rica.

Ruiz, A.; Chapa, T. y Ruiz Zapatero, G. (1988): «La arqueología contextual: una revisión crítica». Trabajos de Prehistoria, 45: 11-17.

SMITH, B.D. (1976): «Twitching" A minor ailment affecting human paleoecolocial research". En C.E. Cleland (ed.): "Cultural change and continuity: Essays in honor of James Bennett Griffin». Academic Press. New York: 275-292.

Sorokin, P. y MERTON, R. (1990): «Social-time: A Methodological and Functional Analysis». En J. Hassard (ed.): «The Sociology of Time». St. Martin's Press. New York: 56-66.

STEWARD, J.H. (1942): «The direct historical approach to archaeology». American Antiquity, 7: 337-343.

Stickel, E. G. y CHARTKOFF, J.L. (1973): «The nature of scientific laws and their relation to law-building in archaeology». En C. Renfrew (ed.): "The explanation 
of culture change: Models in Prehistory.. Duckworth. London: 663-671.

Thompson, R.H. (1958): "Modern Yucatecan Maya Pottery Making». Society for American Archaeology. Memoir 15. Washington.

TILIEY, CH. (ed.) (1994): "A Phenomenology of Landsca. pe. Places, Paths and Monuments». Berg. London.

Vicent Garcia, J. (1990): «El Neolitic: transformacions socials i economiques" En J. Anfruns y E. Llobet (eds.): «El canvi cultural a la Prehistoria». Ed. Colum. na. Barcelona: 241-293.

WILSON. D. (1851): "The Archaeology and Prehistoric Annals of Scotland". Sutherland and Knox. Edimburgo.

Wolf. E. (1955): «Types of Latin American Peasantry: A Preliminary Discussion». American Anthropologist, 57 : 452-471.
- (1968): "Closed corporate peasant communities in Mesoamerica and Central Java". En R.A. Manners y D. Kaplan (eds.): "Theory in Anthropology. A sourcebook». Routledge and Kegan Paul. London: 294-300.

- (1982): “Los campesinos». Nueva Colección Labor, Ed. Labor. Barcelona. $3^{\mathrm{a}}$ ed., $1^{\mathrm{a}}$ reimpresión.

WYLIE, A. (1985): "The reaction against analogy». En M.B. Schiffer (ed.): "Advances in Archaeological Method and Theory". 8. Academic Press. New York: 63-111.

YELLEN, J.E. (1977): "Archaeological approaches to the present. Models for reconstructing the past». Academic Press. New York. 